\title{
doispontos:
}

\section{A democracia deliberativa habermasiana e o déficit de representatividade}

\author{
Cristina Foroni Consani \\ crisforoni@yahoo.com.br \\ Pós doutoranda no departamento de Direito da Universidade Federal do Rio Grande do Norte (UFRN), Natal, \\ Rio Grande do Norte, Brasil
}

\begin{abstract}
Resumo: As teorias da democracia deliberativa formulam uma crítica ao modelo de democracia representativa liberal, pautado em ideais como divisão de poderes, eleições periódicas e regra da maioria, e apresentam propostas de retomada do espaço político como um local para a discussão e deliberação de temas de interesse da coletividade. Um dos principais modelos de democracia deliberativa é aquele elaborado pelo filósofo alemão Jürgen Habermas. Neste trabalho, analisa-se a proposta de política deliberativa habermasiana a partir de três conceitos, a saber: povo, vontade e representatividade. Busca-se apontar alguns problemas desse modelo de política deliberativa e sugere-se modos de complementá-lo.
\end{abstract}

Palavras-chave: Habermas; democracia deliberativa; representação política; representatividade; povo; vontade.

\section{Habermas's deliberative democracy and the representativeness deficit}

\begin{abstract}
The theories of deliberative democracy formulate a critique of the liberal representative democracy model, which is based on ideals such as division of powers, periodic elections, and majority rule. These theories present proposals for resumption of political space as a place for discussion and resolution of collective interest issues. One of the main deliberative democracy models is the one developed by the German philosopher Jürgen Habermas. In this paper, Habermas's deliberative model is analyzed using three concepts, namely, people, will, and representativeness. It is argued that Habermas's model could be complemented in order to become more representative.
\end{abstract}

Key-words: Habermas; deliberative democracy; representativeness; political representation; people; will

\section{INTRODUÇÃO}

Dois modelos de democracia consolidaram-se na filosofia política moderna e contemporânea, a saber, o modelo processualista ou instrumental, associado a Joseph A. Schumpeter, e o modelo deliberativo, associado a Jürgen Habermas. Em ambos os casos, a representação política se coloca como uma questão relevante. Enquanto o modelo processualista baseia-se no princípio da agregação de preferências e da troca periódica dos representantes, o modelo deliberativo pauta-se no princípio da universalidade dos argumentos racionais como critério de legitimidade das decisões políticas dos representantes (cf. URBINATI, 2013, p. 102). Assim, pode-se considerar que, ao reconhecerem os limites do modelo de democracia processualista, as teorias da democracia deliberativa buscam ou oferecer orientações para a transformação das práticas sociais e políticas - como, por exemplo, nas teses de Gutmann e Thompson, ou mesmo propõem a tarefa reconstrutiva da democracia em termos discursivos, como no caso de Habermas (cf. GEENENS, 2007, p. 356). 
Sem caracterizar de forma extensiva a posição e teses das teorias da democracia deliberativa, em linhas gerais pode-se dizer que essas teorias formulam uma crítica ao modelo processualista e à democracia representativa liberal, pautado em ideais como divisão de poderes, eleições periódicas e regra da maioria, no qual a organização do poder político ocorre por meio de mecanismos de agregação de preferências, principalmente pelo voto, buscando-se a conciliação de interesses privados de indivíduos ou grupos com o interesse público.

As críticas apontam para a pouca eficácia desse modelo em apresentar respostas satisfatórias para os problemas que se colocam às sociedades contemporâneas, marcadas pelo pluralismo, pelo aumento da complexidade das tarefas do Estado e pela falta de representatividade política, que levam a uma desvitalização do espaço público. Nesse contexto, as teorias da democracia deliberativa apresentam-se como um modelo normativo, ancorado em princípios e fundamentos que norteiam o processo decisório e que têm entre os seus objetivos a retomada do espaço político como um local para a discussão e deliberação de temas de interesse da coletividade.

De forma geral, apresentam-se como um modelo conciliatório entre ideais contrapostos da teoria política, tais como: a liberdade dos antigos (soberania popular) e a liberdade dos modernos (direitos e liberdades individuais), o substancialismo e o procedimentalismo, o mercado (agregação de preferências individuais) e o fórum (participação política intensa visando o interesse público). ${ }^{1}$

Outro ponto que assume grande relevância da discussão do modelo de democracia deliberativa é a formação da opinião e da vontade política. Essa é também uma questão de extrema relevância quando se coloca em foco a questão da representação política e a forma como ela vem se estabelecendo nas sociedades hodiernas. A representação política quando relacionada à democracia representativa propriamente dita demanda representatividade, o que implica a possibilidade de controle dos eleitores sobre seus representantes.

Na esteira das discussões das teorias da democracia deliberativa, o propósito deste trabalho é discutir a formação da vontade política no contexto das sociedades democráticas contemporâneas. Toma-se como exemplo o modelo de democracia deliberativa proposto por Jürgen Habermas a fim de analisar como o filósofo alemão delimita a relação entre a formação da opinião e a formação da vontade política. Sustenta-se que na proposta habermasiana há um gap entre a formação da opinião na esfera pública geral e a formação da vontade política na esfera pública parlamentar. Considera-se que este gap poderia ser preenchido se, na estrutura político-jurídica criada nas constituições de cada Estado, fossem instituídos canais formais que ligassem, de modo vinculante, a opinião popular à formação da vontade política no poder legislativo.

Antes de dar início à discussão a respeito da formação da opinião e da vontade, entende-se ser necessário discutir qual a concepção de povo e de vontade política que sustentam a proposta que será aqui defendida, haja vista povo e vontade serem conceitos essenciais em qualquer modelo de teoria democrática.

Sendo assim, o estudo a respeito da formação da opinião e da vontade será feito em três momentos: primeiramente, serão apresentados os conceitos de povo e de vontade que orientarão a discussão, os quais são externos à teoria de Habermas; em segundo lugar, será apresentada a proposta de democracia deliberativa habermasiana, precisamente o modo pelo qual é delineado dentro de seu modelo de política deliberativa a formação da opinião e da vontade política, apontando para pontos considerados problemáticos; em terceiro lugar, será apresentado e defendido um modelo de política deliberativa cuja proposta é a criação de canais formais para ligar, de modo vinculante, a opinião popular e a vontade política. 


\section{OS CONCEITOS DE POVO E DE VONTADE}

A definição do conceito de povo é de fundamental importância para as teorias da democracia, pois antes mesmo de se fazer a pergunta "como se participa da política?" deve-se perguntar "quem participa?". Uma definição meramente jurídica do conceito de povo costuma dar uma resposta simples para a questão “quem participa”, isto é, o conceito jurídico de povo é definido pela constituição de cada país, sendo comumente considerados membros do povo aqueles que possuem o status de cidadãos.

Contudo, tal definição é insuficiente quando surge a questão intergeracional, ou seja, o povo é formado apenas pelos cidadãos atuais ou neste conceito devem também ser admitidas as gerações passadas e futuras?

Para examinar esse conceito adota-se a distinção feita por Pinzani entre povo em sentido diacrônico (povo entendido de forma abstrata, compreendendo a geração presente, as passadas e as futuras) e povo em sentido sincrônico (indivíduos concretos que formam neste momento o corpo de cidadãos) (PINZANI, 2013, p. 138-140).

Pinzani equipara o povo diacrônico à vontade geral de Rousseau, aquela que transcende as vontades particulares dos indivíduos, e o povo sincrônico à vontade de todos, equivalente à vontade de todos os indivíduos concretos que formam o corpo de cidadãos em um determinado momento histórico. ${ }^{2}$

Segundo ele, a dificuldade de se assumir a perspectiva do povo diacrônico é a de não se conseguir chegar à definição de vontade geral, pois se torna difícil até mesmo estabelecer quem é o povo. Por outro lado, o risco da perspectiva do povo sincrônico seria o da tirania da maioria ou, para evitar que a maioria seja tirânica, se retira da agenda de debate um rol de temas (os direitos fundamentais) e chega-se justamente ao dilema entre o direito e a política, entre os direitos fundamentais e o princípio da soberania popular.

A fim de fugir dos impasses acima mencionados acredita-se ser melhor desmembrar os conceitos apresentados por Pinzani, separando o conceito de povo do conceito de vontade. Nesse caso, entende-se que a categoria mais adequada para se delinear uma proposta de democracia deliberativa é aquela que pode ser definida como povo sincrônico com vontade diacrônica.

Essa categoria pressupõe um povo que se compreende de forma sincrônica, isto é, que participa da vida política de um país com a possibilidade de discutir temas e criar normas que tenham validade a princípio apenas para si. Mas o povo sincrônico com vontade diacrônica não leva em conta apenas os interesses de sua época. Trata-se de um conceito de povo que pensa não apenas na geração presente ou na maioria, mas que deve levar em conta o legado das gerações passadas e o bem-estar e os direitos das gerações futuras, assim como os direitos e interesses das minorias de seu próprio tempo.

Nessa categoria, o sincronismo relacionado ao conceito de povo permite que a constituição seja considerada um documento vivo e aberto ao processo de mudança. Por outro lado, o elemento diacrônico da vontade oferece a segurança de que a abertura da constituição ao povo não implicará a perda ou a supressão de direitos fundamentais e tampouco a destruição da própria democracia. Este parece ser o conceito mais adequado para uma sociedade que não quer permitir que o aspecto democrático se submeta ao jurídico e que tampouco quer se expor à tirania da maioria. ${ }^{3}$

Sincronismo e diacronismo são conceitos complementares e interdependentes. Sem a contínua possibilidade de mudança introduzida pelo sincronismo a democracia perde a sua essência que é autogoverno popular. Por outro lado, sem o ideal de estabilidade e de aperfeiçoamento proporcionado pelo diacronismo, os resultados produzidos pela ação sincrônica do povo podem causar danos à sociedade e aos indivíduos. 
Desse modo, as instituições democráticas que dão forma ao povo sincrônico são de grande relevância para o ideal democrático, sobretudo porque contribuem para a formação do cidadão à medida que produzem hábitos democráticos. Contudo, apenas a forma democrática criada por uma constituição não consegue lidar adequadamente com os problemas que podem advir de uma ação unicamente sincrônica do povo, como apontado anteriormente.

Por outro lado, também o elemento diacrônico, sozinho, é incapaz de produzir resultados, pois, figurando como conteúdo, ele precisa de uma forma dentro da qual a vontade se expressará. Assim, de nada adianta desenvolver uma excelente metodologia de deliberação e ter um povo altamente esclarecido em um país cuja constituição não ofereça instituições adequadas à participação popular.

É a partir do conceito de povo sincrônico com vontade diacrônica que se pretende travar um diálogo com a política deliberativa habermasiana.

\section{A FORMAÇÃO DA OPINIÃO E DA VONTADE POLÍTICA NO MODELO HABERMASIANO DE DEMOCRACIA DELIBERATIVA}

A relação entre democracia e direito é o principal tema de Faktizität und Geltung, publicado por Habermas em 1992. ${ }^{4}$ Nesse texto, o filósofo alemão dedica-se à elaboração de um modelo procedimental do direito e da política e, para tanto, enfrenta questões tais como a fundamentação legítima do direito a partir de sua gênese no processo democrático e a relação entre os poderes do Estado.

Habermas sustenta que em uma época pós-metafísica a legitimidade do direito deve ser buscada na relação entre a autonomia privada e pública dos indivíduos, ou seja, o direito somente será legítimo se for produzido por meio de um procedimento democrático no qual a soberania popular se fez presente e que ao mesmo tempo preserve os direitos fundamentais dos cidadãos. Assim sendo, a única base aceitável para a formação do direito legítimo é um consenso não-coercitivo e racional entre indivíduos autônomos.

Contudo, o autor considera que a filosofia política moderna e contemporânea não produziu respostas satisfatórias para o problema da tensão entre a autonomia pública, consubstanciada na soberania popular, e a autonomia privada, representada pelos direitos e liberdades fundamentais (HABERMAS, 1997, I, p. 128-139).

Habermas sustenta que essa tensão pode ser solucionada a partir da aplicação do Princípio do Discurso (D) ao processo jurídico de normatização. Segundo esse princípio "são válidas as normas de ação às quais todos os possíveis atingidos poderiam dar o seu assentimento, na qualidade de participantes de discursos racionais"s (HABERMAS, 1997, I, p. 142).

O Princípio do Discurso, cujo conteúdo é normativo, fundamenta-se "nas condições simétricas de reconhecimento de formas de vida estruturadas comunicativamente", ou seja, Habermas parte do pressuposto de que "questões práticas em geral podem ser julgadas imparcialmente e decididas racionalmente" (HABERMAS, 1997, I, p. 143/144). Esse princípio aplica-se a dois campos: à moral e ao direito.

A aplicação do Princípio do Discurso ao direito se dá por meio do Princípio da Democracia, segundo o qual "somente podem pretender validade legítima as leis jurídicas capazes de encontrar o assentimento de todos os parceiros do direito, num processo jurídico de normatização discursiva” (HABERMAS, 1997, I, p. 145). 
Este princípio tem duas finalidades: criar o sistema de direitos e estabelecer a "linguagem que permite à comunidade entender-se enquanto associação voluntária de membros do direito iguais e livres" (HABERMAS, 1997, I, p. 146). É a partir do entrelaçamento entre os princípios do discurso e da democracia com a forma jurídica que Habermas sustenta sua tese de que a autonomia privada e a autonomia pública são cooriginárias. Segundo o autor, a gênese lógica dos direitos ocorre da seguinte maneira:

(...) começa com a aplicação do princípio do discurso ao direito a liberdades subjetivas de ação em geral - constitutivo para a forma jurídica enquanto tal - e termina quando acontece a institucionalização jurídica de condições para um exercício discursivo da autonomia política, a qual pode equiparar retroativamente a autonomia privada, inicialmente abstrata, com a forma jurídica. Por isso, o principio da democracia só pode aparecer como núcleo de um sistema de direitos. A gênese lógica desses direitos forma um processo circular, no qual o código do direito e o mecanismo para a produção de direito legitimo, portanto o principio da democracia, se constituem de modo cooriginário. (HABERMAS, 1997, I, p. 158)

O sistema de diretos deve conter, de modo abstrato, direitos imprescindíveis para que os cidadãos participem do processo democrático em igualdade de condições. Primeiramente, assegura-se a autonomia privada a partir de três categorias de direitos, quais sejam: a) direitos a iguais liberdades subjetivas de ação; b) direitos que garantam o status de um membro igual e autônomo da comunidade jurídica; c) direitos que afirmem a possibilidade de postulação judicial. ${ }^{7}$ Em segundo lugar, assegura-se a autonomia pública conferindo-se (d) direitos de igual participação em processos de formação da opinião e da vontade e de criação do direito legítimo. Por fim, os direitos de autonomia privada e pública implicam (e) "direitos fundamentais a condições de vida garantidas social, técnica e ecologicamente, na medida em que isso for necessário para um aproveitamento" (HABERMAS, 1997, I, p. 159/160), em condições iguais, dos direitos elencados acima.

Sendo esses direitos elencados de forma abstrata, é o processo democrático que irá estabelecer seu conteúdo. O modo pelo qual os cidadãos participarão desse processo de criação do direito legítimo é detalhado por Habermas quando ele delineia o seu modelo normativo de democracia, denominado política deliberativa, o qual é estruturado como uma proposta intermediária entre o modelo liberal e o republicano, os quais são refutados, em parte, pelo autor.

Analisados a partir do ponto de vista da participação e da representação política, os modelos republicano e liberal apresentam perspectivas bastante distintas. Na proposta republicana - que Habermas analisa a partir da teoria de Frank Michelman e acaba por aproximá-la demasiadamente da proposta comunitarista ${ }^{8}$ - há uma forte relação entre liberdade e participação política, abarcando o conceito de autonomia política justamente no sentido rousseauniano, segundo o qual os cidadãos são livres porque se submetem a uma lei por eles aprovada (cf. OLIVEIRA, 2008, p. 18). Nessa perspectiva, o processo de formação da vontade política constitui o próprio ethos da comunidade refletido em cada nova deliberação. Já a proposta liberal compreende a liberdade como ausência de interferência do Estado em assuntos privados e, nesse sentido, a atividade política é vista como uma atividade secundária, que pode ficar a cargo de representantes eleitos e, por conseguinte, não se exige dos cidadãos um exímio controle sobre seus representantes, como exige a teoria republicana (cf. MELO; VITALE, 2008, p. 239/240).

Habermas propõe um modelo de democracia que se define como uma terceira via entre o republicanismo e o liberalismo. Esse modelo assimila elementos de ambas as teorias, buscando criar um "procedimento ideal para a deliberação e a tomada de decisão” (HABERMAS, 1997, II, p. 19).

Habermas filia-se à tradição liberal ao sustentar que a formação do direito faz uso do conceito de justo, ao qual os cidadãos devem chegar por meio do consenso alcançado em uma discussão racional. Nesse sentido, os procedimentos democráticos devem assegurar "resultados neutros, isto é, imparciais: a racionalidade 
procedimental deve garantir justiça no sentido da regulamentação imparcial de questões práticas" (HABERMAS, 2002, p. 303). Do modelo republicano, Habermas conserva a ideia de democracia como um processo comunicativo no qual o papel da formação e da vontade coletiva assume grande relevância.

A proposta habermasiana de um modelo procedimental de democracia pressupõe uma rede de processos comunicativos tanto dentro quanto fora do complexo parlamentar. Esse fluxo comunicacional passa pela formação da opinião pública, através de discussões racionais orientadas ao entendimento e, também por eleições democráticas, reguladas por procedimentos que garantem a validade e legitimidade do processo democrático, alcançando o patamar de decisões políticas em forma de lei, as quais asseguram a conversão do poder comunicativo em poder administrativo através do direito.

Por um lado, Habermas afasta-se do modelo liberal ao propor um procedimento capaz de institucionalizar os pressupostos comunicacionais advindos da sociedade. Por outro lado, difere também do republicanismo ao propor um modelo que se aplica somente ao processo de elaboração das leis, não o estendendo a todas as instituições do Estado. Como o próprio autor explica,

Se a política deliberativa assumisse os contornos de uma estrutura capaz de abranger a totalidade social, o esperado modo discursivo de socialização do sistema jurídico teria que se alargar, assumindo a forma de uma auto-organização da sociedade, e penetrar na sua complexidade (HABERMAS, 1997, II, p. 28/29). ${ }^{9}$

A concepção habermasiana de política deliberativa estabelece condições que o procedimento ideal de tomada de decisão e deliberação tem que respeitar, sendo estas desenvolvidas de forma dual ou bidimensional. O caráter dual da política deliberativa reside na conceituação de espera pública, que é dividida pelo autor em esfera pública parlamentar (onde se forma a vontade política) e esfera pública geral (onde se forma a opinião).

Desta forma, as deliberações devem acontecer dentro de uma esfera pública parlamentar, mas têm como pauta temas advindos de uma esfera pública geral, "da qual é titular o público de cidadãos em geral" (HABERMAS, 1997, II, p. 32).

A esfera pública geral caracteriza-se por sua "estrutura anárquica" que, mesmo estando sujeita aos efeitos da repressão e exclusão do poder social distribuído desigualmente e a distorções que podem surgir nos processos comunicativos, ainda assim tem a vantagem de ser um meio de comunicação livre de limitações e eficaz para captar novas necessidades e problemas, colocando-os sob perspectiva, para que possam ser posteriormente inseridos na agenda parlamentar (HABERMAS, 1997, II, p. 33). Como descreve Werle, "a esfera pública é um sistema de alarme com sensores não especializados, porém sensíveis no âmbito da sociedade" cuja finalidade é "não apenas perceber e identificar os problemas, mas também tematizá-los de modo convincente (...)" (WERLE, 2013, p. 174). Esses temas oriundos do fluxo comunicacional da esfera pública geral serão, então, dentro da esfera pública parlamentar, transformados em leis através de deliberações e, desta forma, atingem o poder administrativo aplicado à sociedade.

Logo, a relação entre esfera pública geral e esfera pública parlamentar estabelece-se a partir das informações e das pressões oriundas da primeira para a segunda, de modo que os temas considerados relevantes sejam inseridos no debate parlamentar. Cabe aos representantes políticos ouvir as vozes oriundas do espaço público e deliberar sobre os assuntos tematizados. Como ressaltado por Pinzani, "a verdadeira democratização do poder ocorre somente quando o fluxo comunicativo entre cidadãos e instâncias decisórias autorizadas se torna um fluxo de poder no qual o poder político informal e o institucionalizado entram em uma relação de feedback" (PINZANI, 2009, p. 152/153). Ou seja, a democratização do poder depende exatamente do quanto a esfera pública parlamentar, por meio dos representantes eleitos do povo, se abrirá para as demandas oriundas da esfera pública geral. 


\section{A VINCULAÇÃO ENTRE OPINIÃO E VONTADE POLÍTICA E A QUESTÃO DA REPRESENTATIVIDADE}

Parece ser possível considerar que os conceitos de povo e de vontade implícitos na teoria habermasiana da democracia podem ser equiparado ao de o povo sincrônico com vontade diacrônica, ou seja, o povo que se compreende de forma sincrônica, isto é, que funda, conseguindo, na qualidade de participante de discursos racionais, chegar a um consenso.

Habermas, assim como outros teóricos de um modelo democrático deliberativo, entende a deliberação como um elemento que qualifica a democracia representativa e, nesse sentido, contribui para a formação de uma vontade em sentido diacrônico. Contudo, parece haver em sua tese um gap entre a formação da opinião na esfera pública geral e a formação da vontade política na esfera pública parlamentar.

Ainda que se possa alegar que um modelo como o de Habermas possibilita um fluxo contínuo e espontâneo, o qual não é alvo de uma suposta ingerência deontológica por parte de uma filosofia normativa ${ }^{10}$, isto é, ainda que se possa afirmar que não cabe ao filósofo estabelecer como um sistema político concreto deve operar, a escassez de institucionalização parece gerar, todavia, uma contradição, ou ainda, um oximoro.

Isso ocorre na medida em que não é possível oferecer garantia de que a deliberação tomada na esfera pública informal de fato irá vincular a esfera pública parlamentar. Nesse sentido, é possível questionar se efetivamente se trata de uma deliberação no sentido de decisão.

A real influência do povo na formação da vontade política pressupõe ao menos dois aspectos. O primeiro aspecto é que haja uma garantia de que diversas posições e argumentos sejam levados em consideração. O segundo, que a escolha da melhor posição tenha passado por um procedimento considerado democrático. A questão é que não havendo um canal formal e vinculante para ligar a opinião do povo à esfera pública parlamentar, a única coisa verificada de fato na política é que certos grupos com maior poder econômico conseguem veicular suas opiniões como se fossem a vontade do povo e como se tivessem passado pelos dois aspectos acima apontados.

É apenas a institucionalização de canais de participação direta que pode garantir tanto uma análise do que o povo sincrônico quer, assim como a formação de uma vontade diacrônica nesse próprio povo. A criação de canais formais de transmissão e vinculação da opinião pública ao parlamento é condição de possibilidade para se falar de tal vontade.

Num contexto de sociedades plurais, esses canais institucionais são essenciais por dois aspectos, a saber: para que o povo descubra o que de fato quer não enquanto indivíduos ou grupos isolados (ruralistas, evangélicos, ambientalistas, socialistas, etc.), mas enquanto coletividade, na medida em que exerce o seu julgamento em uma atividade de confrontação de diferentes argumentos; e para que o Estado saiba qual é a vontade do povo, pois um grupo economicamente poderoso poderia aparentar ser a vontade do povo inteiro ao utilizar-se de meios midiáticos para veicular sua opinião. Habermas está atento para estes problemas, é claro. Mas confia que uma esfera pública mobilizada seja capaz de superar as barreiras de comunicação (HABERMAS, 1997, II, p.32).

Ainda que houvesse esclarecimento político, se não houvesse uma garantia mínima de vinculação da opinião do povo à atuação de seus representantes, ou um modo de controle político dos eleitores sobre os eleitos mesmo durante o mandato, o máximo que se poderia fazer seria esperar pelas próximas eleições. 
A falta de institucionalização dos canais de diálogo torna menos atrativa para os cidadãos a participação em si, uma vez que isso pode reforçar a impressão, já bastante forte nas sociedades democráticas contemporâneas, de que o engajamento em atividades políticas não surte resultados na vida prática (e esse é um dado que pode ser confirmado pela grande quantidade de eleitores que deixam de comparecer às urnas em países nos quais o voto não é obrigatório).

Benjamin Constant já chamara a atenção para o fato de que sem uma garantia mínima de que vale a pena abrir mão de seu tempo e cuidado com assuntos privados para agir no mundo público, o cidadão passa a não ter nenhum estímulo nem mesmo para desenvolver as habilidades necessárias à ação no espaço público (CONSTANT, 1814, p. 820). ${ }^{11}$

Assim, a falta de meios formais de ligação da opinião oriunda da esfera pública à esfera parlamentar na qual é formada a vontade política faz com que um modelo de política deliberativa falhe na formação da vontade diacrônica justamente por ser incapaz de garantir a atuação sincrônica do povo. Na medida em que não há instâncias que garantam a formação de um julgamento que de fato condiga com o interesse público ou coletivo, os indivíduos permanecerão encerrados em seus interesses particulares.

Este gap entre a formação da opinião e a formação da vontade política cria espaço para que os próprios pressupostos comunicacionais de igualdade de participação no discurso sejam violados, haja vista que um poder como o midiático pode fazer uso exatamente das liberdades de expressão e de comunicação para exercer aquilo que Condorcet, ainda no século XVIII, definiu como um despotismo indireto (CONDORCET, 2013, p.30-33).

O despotismo indireto pode se instalar mesmo em países com garantias constitucionais e eleições livres, uma vez que qualquer grupo que detém o poder (legislativo, executivo, clérigos, juízes, exército, homens de negócios, exército, povo) pode exercer uma interferência despótica sobre o governo de maneira indireta e sem modificar sua estrutura político-jurídica.

Isso porque o que está por trás dessa forma indireta de despotismo é a ação, também indireta, de grupos que usam as garantias democráticas (liberdade de expressão e de associação, por exemplo) para influenciar de forma desigual as ações governamentais. Por essa razão o modo como Condorcet define o despotismo abarca não apenas a violação dos procedimentos, mas também as desigualdades na distribuição do poder e da influência social (cf. LUKES e URBINATI, 2012).

Nesse sentido, o gap acima apontado poderia ser preenchido por um modelo de democracia deliberativa que autorizasse a vinculação da opinião (produto da espera pública geral) à vontade (produto da esfera pública parlamentar). Aliás, ao realizar a genealogia do conceito de democracia representativa, Urbinati ressalta que se trata de uma delegação de poder por meio da qual os representados ou constituintes ainda reservam para si poderes de fiscalização e de interferência na ação de seus representantes. Segundo a autora, o melhor modelo de vinculação entre representantes e representados está delineado na obra do filósofo e constitucionalista francês Condorcet. (cf. URBINATI, 2006).

O principal texto de Condorcet que serve de base para a análise ora realizada é o Plano de Constituição de 1793, que é a compilação da filosofia política e da teoria constitucional do autor (CONDORCET, 2013, pp. 63-186).

A grande contribuição teórica de Condorcet para o debate democrático e para a análise da relação entre soberania popular e direitos fundamentais encontra-se naquilo que se pode chamar de pensamento 
institucional. Condorcet erigiu uma teoria constitucional delineando cuidadosamente um conjunto de instituições, isto é, ele institucionalizou vários canais para a expressão da soberania popular, para a limitação do poder, para a resolução de conflitos e concomitantemente para a proteção dos direitos, elaborando uma proposta intermediária entre os posicionamentos favoráveis à retirada dos direitos fundamentais do debate político ou ao exercício da soberania popular sem qualquer proteção a estes direitos.

As instituições e mecanismos que figuram como canais constitucionais pelos quais os conflitos passam são estruturados por meio dos poderes delegados (executivo, legislativo e judiciário), mas também pelos poderes retidos com o povo (direito de censura e iniciativa popular em matéria legislativa, referendum de consulta, direito de petição e direito de provocar o julgamento de funcionários públicos em caso de abuso de poder ou de violação da lei) e os poderes comuns exercidos pelo povo e por seus representantes (revisão constitucional) e são essenciais para o efetivo exercício da soberania popular e, sobretudo, para a manutenção do poder constituinte ativo. Por meio dos poderes retidos confere-se ao povo o direito permanente de decisão e interferência direta nos rumos da política, de modo que a ação popular pode ocorrer tanto pela voz de seus representantes, quanto por sua própria voz quando se fizer necessário, isto é, a participação direta do povo pode ocorrer concomitantemente a sua ação indireta, conciliando-se a democracia representativa com a democracia direta.

Por meio dos poderes comuns o povo é mantido na titularidade do poder constituinte, que pode ser exercido a qualquer tempo, ou seja, o poder constituinte é conservado com o povo e pode ser exercido diretamente por ele tanto ao provocar a revisão constitucional quanto ao ratificar o texto elaborado pela assembleia constituinte. $O$ poder constituinte pode ser exercido mesmo na vigência da constituição $e$, assim sendo, $o$ povo não perde a sua soberania após ter instituído uma constituição.

Desse modo, estabelece-se uma relação distinta entre poder constituinte e poderes constituídos. Nesse sentido, mesmo após a entrada em vigor da constituição, o povo permanece no exercício do seu direito de soberania, podendo atuar de forma direta (e indireta), atual e sincrônica nas decisões políticas. Em outras palavras, são os canais formais de participação popular criados constitucionalmente que conferem o caráter sincrônico ao povo.

A vinculação entre o momento de formação da opinião e a formação da vontade política ocorre por meio da multiplicação dos locais de debate e de deliberação e também de um complexo sistema de aumento do tempo para a tomada de decisões, criando-se, assim, um modo bastante diferenciado de formação indireta da vontade. Ou seja, esse modelo estabelece um modo distinto de democracia representativa, uma vez que concilia participação e representação exatamente por meio de canais formais de vinculação da opinião à vontade política formada no poder legislativo representativo.

As principais instituições responsáveis por esta vinculação são as denominadas assembleias primarias. Essas instituições constituem-se em locais de deliberação e de tomada de decisão política. Em seu Projeto de Constituição para a França Revolucionária, Condorcet idealizou a divisão e subdivisão do território francês em departamentos, comunas, seções municipais e assembleias primárias. A divisão e subdivisão territorial foi pensada no intuito de tornar possível a participação direta e frequente dos cidadãos nos atos de governo, principalmente buscando evitar que as assembleias primárias fossem compostas por um grande número de membros, o que inviabilizaria a participação, a discussão e a deliberação nos moldes idealizados para manter o poder decisório com o povo. 
As assembleias primárias tornam-se, deste modo, as principais instituições de formação da opinião, haja vista ser nelas que os cidadãos deveriam exercer todos os seus direitos políticos (escolha de candidatos, votação em eleições, deliberações, referendos, direito de censura, provocação da revisão constitucional, colocação de funcionários públicos em julgamento). ${ }^{12}$

Nos termos desse modelo de democracia deliberativa, um assunto colocado em discussão em uma assembleia primária, uma vez considerado pelos membros dessa assembleia como relevante e merecedor de ser colocado em pauta em outra esfera de deliberação (o legislativo nacional, por exemplo), obrigatoriamente deveria seguir para avaliação e deliberação em outras assembleias das seções municipais, comunas e departamentos.

Uma vez que a maioria das assembleias primárias das comunas e dos departamentos entendessem ser relevante a inclusão de determinado tema na pauta do legislativo nacional, seria obrigatório, para o legislativo, a discussão e deliberação a respeito do determinado tema. Isso não significa, é claro, que o legislativo deveria decidir do mesmo modo que decidiram as assembleias primárias, mas sim que não poderia deixar de colocar em votação o tema oriundo da discussão e deliberação popular.

Claro que o diacronismo da vontade não se sustenta apenas pela institucionalização dos canais de vinculação da opinião à formação da vontade na esfera pública parlamentar. A institucionalização de canais formais de participação é um instrumento que está mais atrelado à eficácia da ação sincrônica do povo. A formação da vontade diacrônica, por outro lado, está associada a um conjunto de medidas que passam pelo investimento em instrução e educação pública, pela adoção de medidas com o intuito de evitar a concentração do poder econômico e político nas mãos de uma minoria e pela aceitação da tese de que o próprio processo de participação nos debates e deliberações públicas é capaz de esclarecer os cidadãos e favorecer a tomada de decisões em prol do interesse público. Tais critérios são defendidos por Condorcet.

Sobre o esclarecimento advindo do próprio processo de deliberação, Condorcet afirma o seguinte:

\begin{abstract}
Ao examinar a marcha de uma assembleia deliberante, vê-se facilmente que as discussões têm aí dois objetivos bem distintos: aí se discutem os princípios que devem servir de base à decisão de uma questão geral; examina-se essa questão em suas partes diversas, nas consequências que resultariam das maneiras diferentes de decidi-la. Até ali as opiniões são pessoais, todas diferentes entre si: nenhuma, como um todo, reúne a maioria dos votos. Então se sucede uma nova discussão, à medida que a questão se esclarece, as opiniões se aproximam, combinam-se entre si: forma-se um pequeno número de opiniões mais gerais, e logo se pode reduzir a questão em discussão a um número maior ou menor de questões mais simples, claramente colocadas, sobre as quais é possivel consultar a resolução da assembleia, e ter-se-á atingido uma espécie de ponto de perfeição se estas questões forem tais que cada indivíduo, ao responder sim ou não a cada uma delas, tiver verdadeiramente emitido a sua resolução (CONDORCET, 2013, p. 69; grifo meu).
\end{abstract}

Esse entendimento a respeito do potencial esclarecedor do processo deliberativo é defendido e ressaltado também por teóricos contemporâneos da democracia deliberativa. Seyla Benhabib considera que o processo deliberativo é capaz de informar, tornando os indivíduos mais conscientes dos conflitos, o que os compele a uma ordenação coerente. (cf. BENHABIB, 2007, p. 47-79). Do mesmo modo, Bernard Manin considera que "[o] processo de deliberação e a confrontação de vários pontos de vista ajudam a esclarecer a informação e refinar suas próprias preferências" (MANIN, 2007, p. 31). Também os teóricos deliberativos apontam para o elemento constitutivo do processo deliberativo quanto à formação da vontade ou do que se compreende como bem comum. De acordo com Jack Knight e James Johnson "o resultado dos procedimentos democráticos representa um - não $o$ - bem comum” Um "bem comum”, continuam os autores "é moldado, não descoberto. É produzido pelas partes no processo deliberativo e não tem um status normativo único e superior”. (KNIGHT e JOHNSON, 2007, 270). 
Desse modo, parece que uma teoria da democracia deliberativa delineada nos moldes daquela de Condorcet, a qual institui canais formais de ligação da opinião advinda da esfera pública ao poder legislativo no qual a vontade política é formada, consegue lidar melhor com a relação entre sincronismo e diacronismo exatamente porque busca assegurar que, por meio da ação sincrônica do povo, seja formada a vontade política diacrônica.

Nesse sentido, são delineadas não apenas instituições deliberativas, mas também instituições que tornam a representação representativa. A representatividade exige um modelo de representação que não se resume à escolha de um candidato pelos cidadãos em eleições periódicas. Ao contrário, exige a possibilidade de um controle constante e de interferência do representado na atuação dos representantes de modo que os anseios populares sejam inseridos na agenda parlamentar (cf. URBINATI, 2006, p. 47/48).

A teoria habermasiana, assim, embora assuma a grande relevância de um modelo democrático deliberativo, parece apresentar um déficit no que diz respeito à representatividade. Tal déficit está relacionado à ausência de canais formais de vinculação da opinião à vontade política e ao consequente gap entre formação de uma vontade política diacrônica e ação sincrônica do povo.

\section{CONSIDERAÇÕES FINAIS}

O intuito deste trabalho foi analisar em que medida um modelo de democracia deliberativa que não vincula a formação da opinião à formação política da vontade dentro do poder legislativo pode honrar as promessas de revitalização da democracia representativa. Tal proposta de análise tomou como parâmetro o modelo de política deliberativa proposto por Habermas e procurou examiná-lo à luz dos conceitos de povo, vontade e de representatividade.

Apresentou-se, primeiramente, os conceitos de povo em sentido sincrônico e povo em sentido diacrônico conforme definidos por Alessandro Pinzani. Partindo-se desses conceitos, sugeriu-se que um dos principais problemas abordados pela política deliberativa habermasiana, qual seja, a relação emblemática entre direitos fundamentais e soberania popular, poderia ser melhor enfrentado se os conceitos de Pinzani fossem desmembrados em povo e vontade, adotando-se um conceito referência que foi denominado povo sincrônico com vontade diacrônica.

O conceito de povo sincrônico com vontade diacrônica significa que o povo deve ser pensado sincronicamente, isto é, como completamente autorizado a participar da vida política de seu país, a interferir nas decisões e a criar e modificar normas. O diacronismo associado ao conceito de vontade, contudo, deve assegurar que ao participar da vida política o povo sincrônico não leve em conta apenas os interesses da maioria ou de sua própria geração. Pensar a vontade diacronicamente significa pensar nos direitos das minorias e também das gerações futuras.

Ao examinar o modelo de política deliberativa habermasiano à luz do conceito de povo sincrônico com vontade diacrônica, observou-se que, justamente em razão da ausência de canais formais de vinculação da opinião formada na esfera pública geral à vontade política parlamentar, a teoria falha em assegurar a ação sincrônica do povo. Tal falha deve-se ao fato de que, caso o poder legislativo deixe de incorporar em sua agenda as demandas advindas da esfera pública informal, não há meios de obrigá-lo, a não ser esperar o próximo pleito eleitoral. 
Nesse sentido, tal modelo de democracia deliberativa apresenta também um déficit de representatividade. A representatividade pode ser entendida justamente como a possibilidade de os cidadãos interferirem, durante a vigência do mandato, nas decisões políticas de seus representantes.

A proposta de política de democracia habermasiana, assim como outros modelos de democracia deliberativa, são de extrema relevância para a discussão dos problemas que vem sendo enfrentados pela democracia representativa, haja vista sua defesa na retomada do espaço público como um local para a discussão e deliberação de temas de interesse coletivo.

Entende-se, todavia, que tais propostas podem ser ainda mais relevantes para se contrapor a um modelo de democracia representativa que atingiu o seu esgotamento à medida que consigam conciliar deliberação e ampliação da representatividade.

\section{NOTAS}

1. A esse respeito, ver os artigos que fazem parte da coletânea organizada por Denilson Luis Werle e Rúrion Soares Melo. Cf. WERLE; MELO, 2007.

2. A distinção entre vontade geral e vontade de todos é feita por Rousseau no Contrato Social do seguinte modo: "[v] ia de regra, há muita diferença entre a vontade de todos e a vontade geral; esta se refere somente ao interesse comum, enquanto a outra diz respeito ao interesse privado, nada mais sendo do que a soma das vontades particulares." Cf. ROUSSEAU, 1999, p. 37 (Livro II, Cap. III).

3. Entende-se aqui por sincrônico "um conjunto de fatos que coincidem no tempo, sem levar em conta o processo evolutivo" e, por diacrônico "o conjunto dos fenômenos sociais e culturais, etc., que ocorrem e se desenvolvem através do tempo" (Definições dadas pelo Dicionário Houaiss). Esses termos não serão aqui utilizados no sentido clássico a eles atribuído na Linguística por Ferdinand Saussure, uso este que deu origem ao estruturalismo linguístico e que foi posteriormente apropriado pelas teorias estruturalistas na sociologia e na antropologia. O linguista suíço, ao analisar a interferência do fator tempo no desenvolvimento da língua, propôs a divisão da Linguística segundo dois eixos: a) o eixo das simultaneidades $(\mathrm{A} \rightarrow \mathrm{B})$ - "concernente às relações entre coisas coexistentes, de onde toda intervenção do tempo se exclui"; b) eixo das sucessões (C $\downarrow D)$ - "sobre o qual não se pode considerar mais que uma coisa por vez, mas onde estão situadas todas as coisas do primeiro eixo com suas respectivas transformaçõos". O eixo da simultaneidade é também chamado pelo autor de Linguística sincrônica, a qual estuda "tudo quanto se relacione com o aspecto estático". Já o eixo das sucessões é aquele da Linguística diacrônica, relacionado a "tudo que diz respeito às evoluções". Desse modo, a princípio as definições de sincrônico e diacrônico apresentadas na Linguística assemelham-se às definições adotadas neste trabalho, pois indicam respectivamente simultaneidade e continuidade temporal. Contudo, quando Saussure ressalta o aspecto estático da Linguística sincrônica e o evolutivo da Linguística diacrônica, surgem aí elementos dissonantes. Quando analisados a partir do ponto de vista da relação entre constituição e democracia, o termo sincrônico indica sim simultaneidade, mas se opõe ao ideal estático (pois simboliza o direito de um povo atual modificar a sua constituição), ao passo que o termo diacrônico afirma o ideal estático, ou de estabilidade e segurança do ponto de vista jurídico, ou seja, em certa medida recorre-se ao fator tempo para negar ao povo de hoje o direito de fazer mudanças que possam prejudicar o povo de amanhã. Verifica-se então uma alteração dos aspectos estático/evolutivo delineados por Saussure. Cf. SAUSSURE, 2006, 95/96. Agradeço a Leon Fahi Neto por advertir-me a respeito das distinções entre o uso dos termos sincrônico/diacrônico feito pela Linguística e aquele que está sendo adotado neste trabalho.

4. Texto traduzido para o português sob o título Direito e Democracia: entre facticidade e validade (CF. HABERMAS,. 1997). Doravante me reportarei à tradução brasileira. 
5. O autor traz definições dos termos empregados na formulação desse princípio: “O predicado 'válidas' refere-se a normas de ação e a proposições normativas gerais correspondentes; ele expressa um sentido não específico de validade normativa, ainda indiferente em relação à distinção entre moralidade e legitimidade. Eu entendo por 'normas de ação' expectativas de comportamento generalizadas temporal, social e objetivamente. Para mim, 'atingido' é todo aquele cujos interesses serão afetados pelas prováveis consequências provocadas pela regulamentação de uma prática geral através de normas. E 'discurso racional' é toda a tentativa de entendimento sobre pretensões de validade problemáticas, na medida em que ele se realiza sob condições da comunicação que permitem o movimento livre de temas e contribuições, informações e argumentos no interior de um espaço público constituído através de obrigações ilocucionárias" (HABERMAS, 1997, I, p. 142).

6. Grifos no original.

7. Habermas adverte o leitor de que essas três primeiras categorias de direitos ainda não podem ser entendidas como direitos liberais que protegem os cidadãos contra o Estado, haja vista eles serem colocados em um momento anterior à organização jurídica de um poder estatal. Eles regulam apenas as relações entre civis livremente associados e estabelecem direitos e obrigações recíprocas (Cf. HABERMAS, 1997, I, 159).

8. Sobre as diferenças e pontos entrelaçados entre liberalismo, republicanismo e comunitarismo, ver TAYLOR, 2000, pp. 197-220. O republicanismo constitucional, como sustentado por Michelman, apóia-se em certa medida na tradição, mas sustenta que o uso da tradição deve ser feito com base em um compromisso com normas gerais, de modo a evitar qualquer tipo de apelo ao comunitarismo e a valores éticos. Ao sustentar isso, Michelman oferece uma resposta para as críticas feitas por Habermas que vincularam sua teoria a uma eticidade comunitária. Cf. MICHELMAN, 1999, 68-70.

9. Grifos no original.

10. Agradeço a sugestão de Denilson Luis Werle a respeito deste aspecto de uma política deliberativa não institucionalizada.

11. Constant manifesta esse entendimento em um texto no qual analisa o tribunal do júri, defendendo essa instituição das críticas que lhe são dirigidas. O autor sustenta que: "Em razão dos costumes existentes uma instituição pode inicialmente parecer pouco convincente, mas se ela for intrinsecamente boa, então a nação adquire por meio dela uma capacidade que antes não tinha" (Cf. CONSTANT, 1814, p. 80). Stephen Holmes interpreta essa passagem justamente no sentido de que o povo não irá desenvolver uma capacidade se esta não for necessária (Cf. HOLMES, 2009, p. 63). Esse mesmo raciocínio pode ser aplicado às práticas democráticas, haja vista que os cidadãos não se sentirão motivados para participar das práticas democráticas e deliberativas se não houver nenhuma garantia de que seus posicionamentos serão incorporados à agenda parlamentar.

12. O Título III do Projeto de Constituição trata da organização das assembleias primárias. Essas instituições deveriam ser distribuídas por todo o território e cada uma delas deveria ter inscrito em seus quadros no mínimo 450 e no máximo 900 membros. Após formada a assembleia primária deveria ser constituído um escritório para coordenar os trabalhos. Esse escritório deveria ser formado pelos membros da própria assembleia primária, à proporção de um membro para cada 50 cidadãos inscritos no quadro da assembleia. Os membros que compõem o escritório deveriam ser renovados a cada nova convocação da assembleia primária. Cf. CONDORCET, 2013, p. 132-142.

\section{REFERÊNCIAS BIBLIOGRÁFICAS}

BENHABIB, Seyla. 2007. Sobre um modelo deliberativo de legitimidade democrática. In: WERLE, Denílson Luis, MELO, Rúrion Soares (orgs). Democracia Deliberativa.São Paulo: Editora Singular, Esfera Pública, pp. 47-79. 
CONDORCET, Jean-Antoine-Nicolas de Caritat de. 2013. Escritos politico-constitucionais. Organização, apresentação e tradução de Amaro de Oliveira Fleck e Cristina Foroni Consani. Campinas: Editora da Unicamp.

CONSTANT, Benjamin. 1814. Refléxion sur les constitutions. Paris: Hocquet.

GEENENS, Raf. 2007. The deliberative model of democracy: two critical remarks. In: Ratio Juris, v. 20, no 3, pp. 355-377.

HABERMAS, Jurgen. 2002. A inclusão do outro: estudos sobre teoria política. Tradução de George Sperber e Paulo Astor Soethe. São Paulo: Edições Loyola.

1997. Direito e Democracia: entre facticidade e validade.Volume I e II. Tradução de Flávio Beno Sieveneichler, Rio de Janeiro: Tempo Brasileiro.

HOLMES, Stephen. 2009. The Liberty to Denounce: Ancient and Modern. In: The Cambridge companion to Constant. Edited by Helena Rosenblatt. New York: Cambridge University Press, pp. 47-68.

KNIGHT, Jack e JOHNSON, James. 2007. Agregação e deliberação. In: WERLE, Denílson Luis; MELO, Rúrion Soares (orgs). Democracia Deliberativa.São Paulo: Editora Singular, Esfera Pública, pp. 253-276.

LUKES, Steven; URBINATI, Nadia. 2012. Editors Introduction. In: CONDORCET. Political Writings. Edited by Steven Lukes and Nadia Urbinati. New York: Cambridge University Press, pp. xv-xlii.

MANIN, Bernard. 2007. Legitimidade e Deliberação Política. In: WERLE, Denílson Luis, MELO, Rúrion Soares (orgs). Democracia Deliberativa.São Paulo: Editora Singular, Esfera Pública, pp. 15-45.

MELO, Rúrion Soares; VITALE, Denise. 2008. Política Deliberativa e o Modelo Procedimental de Democracia. In: NOBRE, Marcos; TERRA, Ricardo (Orgs). Direito e Democracia: Um guia de leitura de Habermas. São Paulo: Malheiros, pp. 223-247.

MICHELMAN, 1999. Frank I. Brennan and Democracy. Princeton, New Jersey: Princeton University Press.

OLIVEIRA, Nythamar. 2008. Mundo da Vida, Ethos Democrático e Mundialização: A Democracia Deliberativa segundo Habermas. In: Doispontos, v. 5, n. 2, pp.49-71.

PINZANI, Alessandro. 2013. Democracia versus tecnocracia: apatia e participação em sociedades complexas. In: Lua Nova , no 89, pp. 135-168.

. Habermas. 2009. Porto Alegre: Artmed.

ROUSSEAU, Jean-Jacques. 1999. O Contrato Social. Tradução Antonio de Pádua Danesi, 3ª Ed. São Paulo: Martins Fontes.

SAUSSURE, F. de. 2006. Curso de Linguística Geral. 27. ed. São Paulo: Cultrix.

TAYLOR, Charles. 2000. Propósitos entrelaçados: o debate liberal-comunitário. In: Argumentos Filosóficos. São Paulo: Edições Loyola, pp. 197-220. 
URBINATI, Nadia. 2013. Da democracia dos partidos ao plebiscite da audience. In: Lua Nova, n. 89 , pp. 85-105.

.2006. Representative Democracy. Principles and Genealogy. Chicago: Chicago University Press.

WERLE, Denilson Luis; MELO, Rúrion Soares (orgs). 2007. Democracia Deliberativa. São Paulo: Editora Singular, Esfera Pública.

WERLE, Denilson Luis.2013. Razão e Democracia - Uso Público da Razão Política e Política Deliberativa em Habermas. In: Trans/Form/Ação, v. 36, pp. 149-176. 